\title{
Dworkin desde la tradición romano-germánica
}

\section{Francisco Tortorelo Cervantes}

\begin{abstract}
The phrase "rule of the judges" has become common as a criticism that refers to constitutional judge's decisions, which seem to contradict the will of the legislators. The constitutional order must then be attentive that the constitutional interpreters do not exercise an overly participative role in the political decisions of each country. Therefore, the interpreting activity should evolve around values that are established in the Constitution and not around what individual judges understand as objective morality. For this reason, it is necessary to promote that constitutional judges are inspired by principles and directions that guide the applications of their decisions. Ronald Dworkin's work explores this normative criteria that can reduce judicial discretion and this article analyzes how to apply his ideas to this subject in the Roman-Germanic tradition of law.
\end{abstract}

En el contexto del derecho romano-germánico, el siglo XX anunciaba el predominio del jus-positivismo sobre las lecturas jus-naturalistas de la realidad normativa. Y aunque aparecieron otras visiones, como el realismo jurídico por ejemplo, que pretendían inyectar nuevos bríos al avance de las concepciones del derecho, estos intentos acabaron por mostrarse demasiado específicos, acaso aplicables al mundo normativo anglo-sajón. En la actualidad, el desarrollo del positivismo jurídico se encuentra en crisis, o si se prefiere, en un declive que no ha disminuído desde fines de la segunda guerra mundial.

Frente al aparente desinterés por relanzar el debate, surgió la posición de Ronald Dworkin. Desde hace unos treinta años, este profesor que divide su actividad académica anual entre la Universidad de Nueva York (NYU) y el University College (UCL) en Londres presenta una lectura crítica del positivismo jurídico, de la que nosotros retomaremos sólo algunos aspectos que, aunque previstos para funcionar en el ámbito de la tradición del common law, 
nos parecen aplicables a la llamada política jurisprudencial. ${ }^{1}$ Es posible que la propuesta teórica de Dworkin pueda servir como puente entre dos tradiciones jurídicas. Si bien nos parece que ninguna lectura de la filosofía del derecho contemporáneo manifiesta un interés deliberado de probar la existencia o inexistencia de una moral objetiva que sirva como eje ordenador del derecho, parece menos contestable que la interpretación constitucional tiende a homologar la comprensión del derecho en el mundo occidental. Y es que la interpretación de la Constitución tiene por objeto llegar a una solución definitiva, al menos en la última de las instancias judiciales.

Desde hace relativamente poco tiempo, los intérpretes constitucionales advierten la necesidad de mirar más allá de las fronteras interpretativas, si no de cada país, al menos de cada tradición jurídica. A partir de decisiones recientes de la Corte Suprema de los Estados Unidos, como aquella que establece que las legislaturas locales no pueden publicar leyes que sancionen penalmente las relaciones homosexuales voluntarias entre adultos, ${ }^{2}$ por primera vez se invoca una decisión de la Corte Europea de los Derechos Humanos para ser aplicada en el estricto medio interpretativo estadounidense. Ronald Dworkin parece conducir a la búsqueda de legitimidad, in extremis, en la comunidad internacional. ${ }^{3}$ Es posible entonces que un esquema semejante podría ser de utilidad para entender mejor los desarrollos que podrá observar en los próximos años nuestra tradición jurídica del civil law. Con ese propósito, enunciaremos a continuación algunas ideas que acaso permitirían a los europeos y latinoamericanos a emprender el camino de regreso, a saber, plantear lo que Dworkin explica en términos de "integridad" del orden normativo a efecto de encontrar la mejor de las lecturas posibles a un postulado constitucional, y por qué no, entender

$44 \quad{ }^{1}$ La noción de política jurisprudencial ha sido formulada en Francia por un anterior presidente de la Corte de Casación y actual miembro del Consejo Constitucional. En aquel país de añeja tradición interpretativa, el jurista Bruno Oppetit señalaba recientemente el rol creador de la casación francesa de los pasados dos siglos, la describía como el tránsito “...de una prerrogativa de justicia retenida, luego de centinela que mantiene la vigencia de las leyes, a un medio de regulación de la realización judicial del derecho", cit. por Canivet, Guy, "La politique jurisprudentielle", documento de trabajo de la Corte de Casación, en: http://www.courdecassation.fr/IMG/File/ pdf_2007/publications_2007/la_politique_jurisprudentielle.pdf (consultado por última vez el 15 de enero de 2008).

${ }^{2}$ Lawrence v. Texas, 539 U.S. 558, 577, 123 S. Ct. 2472, 156 L. Ed. 2 d 508 (2003). Esta sentencia, echa abajo el criterio establecido en 1986 por el mismo tribunal en Bowers v. Hardwick, 478 U.S. 186 (1986). Hasta este momento, eran 12 los estados norteamericanos que habían establecido leyes que sancionaban esas prácticas sexuales por considerarlas anormales.

${ }^{3}$ Dworkin, Ronald, "From Justice in Robes to Justice for Hedgehogs", Conferencia con motivo de la entrega de la Medalla Héctor Fix Zamudio, Instituto de Investigaciones Jurídicas, UNAM, 23 de noviembre de 2006. 
el derecho nacional de estos países a partir de interpretaciones que han hecho avanzar la concepción del derecho en otras latitudes.

Para fundar nuestra propuesta voy a remitirme a algunos aspectos de la teoría de Dworkin que me parecen aplicables en el contexto del derecho continental europeo (que sobra decir, funda la esencia de nuestras tradiciones latinoamericanas). Para ello, abordaré tres ideas principales. Primero, que dentro del ámbito del modelo de derecho romano-germánico nos encontramos en un momento propicio para mirar hacia fuera. En todo caso, los tribunales constitucionales europeos y latinoamericanos parecen dar pasos en esa dirección. Segundo, que esa tendencia pudiera salirse de cauce, al otorgar a los intérpretes constitucionales un papel demasiado participativo en las decisiones fundamentales, por lo que esta tendencia tendría que evolucionar en torno a valores establecidos en la constitución y no en torno a lo que los jueces entiendan individualmente como moral objetiva. Estimamos en cambio que esos criterios normativos y su racionalidad pueden eventualmente ser capaces de reducir la discrecionalidad judicial al servir de criterios estándar de decisión. Por último, nos preguntaremos si en la delimitación de esos estándares normativos pueden o no intervenir los propios jueces.

\section{Momento propicio para estudiar a Dworkin desde la tradición romano- germánica}

La medición de los conflictos de interés dentro de los sistemas políticos contemporáneos remite, de forma natural, a preguntarse si los tribunales constitucionales europeos actúan deliberadamente con el propósito de mejorar el funcionamiento de las asambleas parlamentarias. Mientras que una parte de la clase política de aquel continente se asumía desconfiada ante el fenómeno de la "juridización de la política”, cuya manifestación se traduce en promover el cliché del "gobierno de los jueces", otra parte pugnaba por dotar de más atribuciones a la rama jurisdiccional. Acaso podía siempre encontrarse un punto común, a saber, la exigencia de delimitar el papel interpretativo que deberían asumir de ahora en adelante los jueces constitucionales.

Ante esta dualidad de opiniones, la solución a los procesos constitucionales entre posiciones partidistas no sería planteada en términos arbitrarios. Por el contrario, la protección concedida a los diversos grupos parlamentarios podía legitimarse en la medida en que se funda en ciertos parámetros, es decir, en valores plasmados previamente en la Constitución material. Al defender estos parámetros y preferir la defensa de ciertos valores sobre otros (acaso superpuestos), la justicia constitucional parece asumir un carácter voluntarista. Al delimitar los valores de la Constitución, el intérprete constitucional europeo ha desarrollado algunas herramientas interpretativas que le permiten sortear y su- 
perar con creces la rigidez de los lineamientos emanados de esquema formalista del texto constitucional. ${ }^{4}$ Es así como, al resguardar valores, las jurisdicciones constitucionales ocupan un lugar eminente, mucho más extendido que el que correspondería a la protección de la estructura rígida de la norma, como lo es la Constitución. Esa actividad dirigida a acercar las nociones de Constitución formal y material, a la manera de un "proceso circular de dos polos", ha sido planteada desde hace relativamente poco tiempo.

En la relación entre la Constitución en sentido material y en sentido formal (que es, normalmente de integración, y excepcionalmente de tensión), se encuentra un núcleo que es lo que induce a la ciencia constitucional a asumir como objeto de los preceptos constitucionales las circunstancias históricas relacionadas con el aspecto material, y no solo con aspectos derivados de la política partidista. Otros aspectos distintos, como lo que deba contener la legislación, reflejan los contenidos de las estructuras actuales impuestas a las diversas formas de desarrollo de la legislación; de las formaciones partidistas, de sus programas y resultados electorales; de la presencia de grupos políticos cuyos contenidos son diversos a los de los partidos y de los de aquéllos que estuvieran formalmente reconocidos; de la interpretación constitucional, y particularmente, a aquélla impuesta por la jurisdicción constitucional. ${ }^{5}$ La nueva relación entre las dos manifestaciones de la constitución (en sentido formal y material) plantea pues la posibilidad de involucrar intereses meta-constitucionales o extra-constitucionales, como lo son en el ámbito parlamentario, los contenidos de los programas de gobierno, de carácter eminentemente partidista.

La rigidez aparente del texto fundamental empezó a ser suavizada gracias a la intención deliberada de los tribunales por introducir aspectos extra-constitucionales. Y aunque algunos reaccionaron contra esta tendencia, la intervención judicial no debía ser vista con tanta sorpresa. En su sentido primigenio, desde el siglo XIX inclusive, la consolidación del Estado de Derecho requirió que la sumisión de la administración a la ley quedara confiada al arbitrio de tribunales. Luego, en una fase posterior, la sumisión del legislador a los preceptos constitucionales no sería posible sin la intervención de los tribunales constitucionales. ${ }^{6}$ Empero, aunque esta larga fase de consolidación del rol interpreta-

\footnotetext{
${ }^{4}$ Dentro de estas herramientas podemos mencionar, sin ser exhaustivos, las reservas de interpretación en Francia, las sentencias manipulativas o aditivas en Italia, las instrucciones al legislador en Alemania o el señalamiento de omisiones legislativas en España. Para una visión de conjunto sobre estas cuestiones, véase Aja, Eliseo (ed.) Las tensiones entre el Tribunal constitucional y el legislador en la Europa actual, Barcelona, Ariel Derecho, 1998.

${ }^{5}$ Zagrebelsky, Gustavo, "Considerazione sulla fortuna attuale della dottrina della Costituzione in senso materiale”, en Studi in onore di Leopoldo Elia, Milano, Giuffrè editore, 1999, pp. 1803-1805.

${ }^{6}$ Cappelletti, Mauro, "La corte costituzionale nel sistema di governo italiano e nei rapporti con
} 
tivo de los jueces europeos durante el pasado medio siglo ha transcurrido de manera sostenida, los tribunales constitucionales de aquel continente siguen dando de qué hablar entre los teóricos, que con frecuencia reaccionan contra el fenómeno de la juridización de la política. Y sin embargo, pocos son quienes miran hacia fuera de la tradición del derecho romano-germánico en búsqueda de soluciones doctrinales.

En el marco continental, existe un interés poco constante entre los teóricos por los desarrollos metodológicos que se han originado en el contexto del common law. Este aparente desinterés no está sin embargo reñido con haber escapado, de una vez por todas, de la añeja concepción de Montesquieu de que los jueces son la boca que pronuncia las palabras de la ley. La interpretación constitucional europea ha concluido, de manera inequívoca, que la aplicación de la constitución no es un acto mecánico. Y aún así, múltiples dudas aparecen cuando una hipótesis normativa sobrepasa ciertos parámetros de "normalidad" continental. Cuando el precepto legal es claro y no aparecen dudas respecto a su aplicación, el juez tiene la obligación de leer su contenido en forma unívoca o inequívoca. Pero, ¿qué ocurre cuando existen varias interpretaciones posibles del mismo precepto? La interpretación "constructiva" del derecho, tal como ha propuesto Ronald Dworkin, supone que el intérprete no puede escapar a la ambigüedad de un contenido normativo particular si no es al establecer criterios "estándar" que normalicen la aplicación del precepto en cuestión. Sólo esta clase de criterios puede arrojar una respuesta "correcta", o "right answer" según la terminología dworkiniana, al caso concreto que acepta más de una lectura jurídicamente válida.

Al tratar de la aplicación de estos criterios interpretativos al contexto europeo, abordaremos esta clase de criterios "estándard" como lo ha planteado su autor, en forma de reglas, principios y políticas. En este trayecto, asumimos que la diferenciación entre cada especie de estos parámetros no puede ser definida de manera arbitraria por los intérpretes constitucionales. Estimamos que puede plantearse la existencia de una especificidad que permita a los sistemas continentales evaluar el interés de ganadores y perdedores del juego parlamentario para acudir ante estos tribunales a reclamar por vía jurídica lo que ya se perdió por vía del voto en la asamblea. En este sentido, nos parece relevante señalar que la dinámica parlamentaria de Europa ha contribuído a esclarecer la interpretación de aquéllos ordenamientos constitucionales.

l'ordinamento comunitario", Rivista di diritto processuale, no. 4, 1981, pp. 613-615 (tr. esp. por L. Dorantes, en La justicia constitucional, México, UNAM, 1987). 


\section{Tres estándares normativos en el marco del civil law}

Al señalar una clara distancia entre los teóricos de derecho continental frente a los del common law, la cual podría plantearse como mutuo desinterés, no pretendemos que los criterios anglo-sajones sean asimilados sin reservas al contexto del derecho continental. Pero un acercamiento entre ambos sistemas tampoco nos parece imposible. ${ }^{7}$ Basta referir que desde hace unos años, algunos condicionamientos impuestos al juez europeo, como por ejemplo las normas comunitarias, obligan cada vez más al juez constitucional de aquel continente a interesarse en métodos de trabajo que más bien estarían identificados con la forma de proceder de los tribunales ingleses o estadounidenses.

Si las cortes constitucionales europeas continúan una tendencia que acaso las orientara hacia la creación de derecho, tal intención debería alejarse de cualquier propósito judicial deliberado de ejercer la función legislativa. Las lecturas más difundidas entre los teóricos europeos, como la conocida del "gobierno de los jueces", coinciden en que la invasión que llevan a cabo los jueces constitucionales de la esfera legislativa representa una usurpación de la voluntad soberana del pueblo. ${ }^{8}$ Frente a la típica objeción del juez-legislador, debemos advertir, en primer lugar, que los tribunales no pueden iniciar una acción en justicia por sí mismos, y por otro, que éstos no tienen la última palabra: el legislador puede intervenir, y de hecho lo hace con cada vez más frecuencia, después de dictada una sentencia de estos tribunales, a manera de rectificación de lo anulado judicialmente. ${ }^{9}$ La actividad interpretativa de los tribunales y su carácter técnico son entonces suficientes para neutralizar esa clase de ataques contra la función jurisdiccional. Pero también, en tanto el sistema político aspira a implementar objetivos específicos a cada momento de su historia, como el control de la inmigración ilegal o el pleno empleo, la distinción de los 48 tres "estándares" dworkinianos con los que el juez puede definir el contenido normativo de una pieza de legislación permite establecer un paralelo con la liga funcional de la propia norma; y lo anterior no sólo en el contexto del common law, sino también en el de Europa continental.

\footnotetext{
7 "Por más profunda que parezca la diferencia entre los países de derecho escrito y los del derecho común (common law) la función creadora no se encierra únicamente en los países del segundo grupo, aún cuando ésta se encuentre presente allá de manera más habitual que en los países de la primera categoría. Una evolución convergente tiende a acercar ambas tradiciones”, Rigaux, François, La loi des juges, Odile Jacob, Paris, 1997, p. 127.

${ }^{8}$ Ardant, Philipe, Institutions politiques et droit constitutionnel, 10a. ed., Paris, LGDJ, 1998, p. 97.

${ }^{9}$ Favoreu, Louis, "La légitimité du juge constitutionnel”, Revue Internationale de Droit Comparé, no. 2, 1994, p. 178.
} 
Una regla se aplica de manera sistemática: desde el momento en que, según el intérprete, la hipótesis normativa se actualiza en el mundo exterior. ${ }^{10} \mathrm{Si}$ el contenido deóntico de esta regla fuera invariable, la hipótesis normativa sería terminante. El juez tendría poco que hacer ante silogismos categóricos, y el postulado mencionado del "juez boca de la ley" tomaría sentido de forma inequívoca. En cuanto a los principios, estos no son manifiestos e inequívocos, por lo que exigen del intérprete un conocimiento conjunto del orden normativo. La coexistencia colectiva debe plantearse, en este sentido, a partir de contenidos intrínsecamente justos, más aún cuando una pluralidad de intereses jurídicos legítimos se enfrentan entre sí. Tales principios denotan entonces una proyección mucho más amplia que la que se centraría en la dimensión puntual del caso controvertido en cuestión. ${ }^{11}$ Finalmente las políticas o directrices refieren la jerarquía con la que debe ubicarse cada uno de los valores (o mejor dicho, principios) reconocidos por una norma al momento de resolver la controversia en cuestión. Y es que sabemos que con frecuencia, dos principios pueden entrar en colisión, como por ejemplo libertad e igualdad.

Como primera reacción ante esta formulación tripartita, advertimos su difícil adaptación al contexto continental a falta de desarrollos teóricos capaces de encuadrar sus fundamentos. ${ }^{12}$ Denunciamos esta carencia pues al optar por una jerarquía específica para cada regla, cada sistema jurídico confiere al intérprete constitucional la posibilidad de imponer ciertas consecuencias que él estima más relevantes, y de sacrificar acaso al mismo tiempo el cumplimiento de otros objetivos constitucionales, que probablemente se vuelvan incompatibles con la lectura efectuada de manera predominante hasta ese momento. Ahora bien, el mencionado predominio de unos principios con el consiguiente sacrificio de otros no depende de la voluntad única del juez. El intérprete debe obedecer, según esta propuesta teórica, a las exigencias prácticas, léase los problemas prioritarios que plantea la colectividad en el momento de resolver la contro-

\footnotetext{
${ }^{10}$ Dworkin, Taking Rights Seriously, 2a. ed, Cambridge, Harvard University Press, 1978, p. 24

${ }^{11}$ Greenawalt, Kent, "Policy Rights and Judicial Decisions", en Cohen, Marshal (ed.), Ronald Dworkin and Contemporary Jurisprudence, New Jersey, Totowa, 1984, p. 88.

${ }^{12}$ En Francia, es raro encontrar que se pretendan establecer ligas teóricas entre las tradiciones jurídicas continental y anglosajona, aunque algunas aproximaciones nos parecen relevantes. En su particular manera de entender el derecho, Michel Troper propone una distinción entre el "texto", esto es, la disposición normativa y la "norma", la interpretación dominante al momento en que ésta es aplicada. Según el profesor de Nanterre, sólo esta segunda categoría tiene significado para el mundo del derecho. Al ser entonces emanación directa de un actor que él mismo refiere como "intérprete auténtico" de la norma, el enunciado producido por el intérprete se convierte de esta manera, según su autor, en la única fuente posible de derecho objetivo. Troper, Michel, "Le problème de l'interprétation et la théorie de la supralégalité constitutionnelle", Mélanges Charles Eisenmann, París, Cujas, 1975, p. 131.
} 
versia. De esta manera, la creación de reglas que contienen principios otorgan al individuo una certeza: al surgir conflictos respecto de la interpretación del derecho, éstos se resolverán de acuerdo a lo que concuerde con un trayecto institucional previsible, que refleje una interpretación coherente. De esta manera, el estándar según el cual el número de accidentes de automóvil debe ser disminuido es una política, en tanto que aquél que establece que nadie debe tomar ventaja de su propia conducta nociva es un principio. La diferencia entre ambos puede diluirse si se interpreta al principio como el elemento para delimitar un fin social, es decir, el fin de una sociedad en la que nadie se aprovecha de sus propias conductas nocivas. Tenemos el mismo caso si se atribuye a una política el significado de un principio, a saber, el principio según el cual el fin que subyace en aquélla política es digno de ser alcanzado. ${ }^{13}$

En resumen, un principio debería ser entendido en oposición a una política, y no en contra del funcionamiento de una regla. ${ }^{14}$ De esta manera, los principios corresponden al ámbito del derecho, y no de la política. ${ }^{15} \mathrm{Si}$ el juez debe decidir controversias que derivan del ámbito político, como es el caso de manera creciente en los últimos 50 años en Europa, su intervención se entendería limitada a la defensa de principios, y no de políticas. En el contexto europeo podríamos empezar por adaptar la lectura de la creación de derecho por principios al asumir que la tradición obliga a estos jueces a llevar a cabo su papel interpretativo primero como creadores, o mejor dicho como integradores, de reglas y luego como creadores de principios. Ahora bien, ¿y por qué no de políticas o directrices?

\footnotetext{
${ }^{13}$ Dworkin, Ronald, Op. Cit. 1978, pp. 22-23.

${ }^{14}$ Dworkin ejemplifica la forma como son creados los principios con un ejemplo. La validez de un testamento podría, según él, ser refutada cuando puede extraerse, del contenido de los hechos, que tales situaciones podrían modificar la manera como deba interpretarse la regla aplicable a la controversia. En el caso Riggs v. Palmer, de 1889, la confirmación de este principio es lo que, según Dworkin, condujo a la Corte Suprema de los Estados Unidos a impedir que un asesino pudiera recibir los bienes de una herencia en tanto que se trataba de su propia víctima mortal. Dejando de lado las disposiciones del testamento, válido en su calidad de regla, este tribunal agregaba un nuevo principio al contenido del common law. De ahora en adelante, en virtud de este nuevo principio creado por la Corte Suprema, se entendía que "nadie puede estar autorizado a obtener un lucro de su propia falta o adquirir bienes de su propio crimen”, Dworkin, Ronald, cit. n. 10 y A. Casamiglia, "Prólogo", en Dworkin, R. (1984), Los Derechos en Serio, tr. por M. Gustavino, Barcelona, Ariel Derecho, pp. 7-29.

${ }^{15}$ Dworkin, Ronald, A Matter of Principle, Cambridge, Harvard University Press, 1985, p. 25.
} 


\section{El juez constitucional europeo, creador de estándares normativos}

Desde la perspectiva del positivismo jurídico, doctrina que sin duda dominó la lógica normativa europea del siglo XX, una regla pertenece al sistema normativo en vigor no tanto en razón de su contenido intrínseco, sino de su proceso de creación. El derecho puede albergar toda clase de contenido, ningún comportamiento humano no es ajeno a volverse objeto de una norma jurídica. Una norma jurídica es válida en tanto sea creada de manera particular, a saber según unas reglas preestablecidas y un método específico. ${ }^{16}$

Aunque con frecuencia pueda identificarse una especie de coincidencia accidental entre la ley, es decir, las reglas, y los principios que estructuran al modelo de democracia parlamentaria europea, el aplicador no puede evitar que ciertas ambigüedades normativas aparezcan en el ámbito del derecho. Si asumimos que el espíritu positivista del orden normativo es por definición una visión limitada de la realidad, el juez europeo utiliza ciertos conceptos normativos que le permiten dotar al orden normativo de una extensión modulable. Se trata pues de advertir la existencia de normas "que no funcionan como reglas, pero que operan como principios, políticas o como otra clase de estándares". ${ }^{17}$ En el momento de la aplicación de los preceptos, el juez europeo pareciera interpretar al principio siempre con mayor amplitud de lo que podría atribuir al contenido de la regla. Y es que el principio es válido también para los casos que no han sido previstos dentro de la hipótesis normativa de la regla. Cuando un principio entra en conflicto con otros, la solución debe siempre ser pronunciada por un juez, evidentemente después de haber medido y pesado la importancia recíproca atribuida a cada uno. La noción de "peso" y de "importancia” que subyace de este ejercicio aparece necesariamente separada del ámbito de las reglas. ${ }^{18}$

Lo que determina la razón de ser de una regla es su forma de emisión, es

${ }^{16}$ Kelsen, Hans, Théorie pure du droit, tr. por H. Thévenaz, Neuchâtel, 1953, p. 114.

${ }^{17}$ Dworkin, Ronald, Prendre les droits au sérieux, tr. por M.J. Rossignol, Presses Universitaires de France, Paris, 1995, p. 79.

${ }^{18}$ En su más reciente libro, Dworkin reconoce haber en parte contribuido a la confusión que se generó dentro de los conceptos de derecho del mundo anglo-sajón. Y es que es cierto que toda comunidad política va generando un conjunto de reglas y otros estándares normativos que se oponen con toda claridad a otra categoría de estándares, de carácter más bien moral o consuetudinario; ver por ejemplo, Dworkin, Ronald, Law's Empire, Cambridge, Harvard University Press, 1986, pp. 250-254. Pero en realidad, continúa Dworkin, la intención de separar estos tres estándares jurídicos no ha tenido por objeto proponer una nueva "taxonomía" de los conceptos del derecho. Para él, se trata en cambio de poner en jaque, directamente, al positivismo jurídico. "Elaboré el argumento doctrinal consistente en que no podemos entender a las controversias y a los argumentos 
decir, que su creación ha sido apegada a las formalidades del procedimiento de creación de derecho. Por su parte, lo que determina la razón de ser de un principio es su contenido propiamente dicho. Es pues en función de esta indeterminación, o mejor dicho, de la posibilidad de adaptar progresivamente un principio, que se construye su propio peso específico, esto es, su valor operativo. Si se analiza la jurisprudencia constitucional europea del pasado medio siglo, no es remoto entender que de manera semejante a la práctica judicial anglosajona, "los principios ofrecen al derecho una posibilidad de adaptación y nuevas soluciones, que la regla por sí misma no sería capaz de ofrecerle; los principios no son más que direcciones que se trazan hacia la ruta de una solución". ${ }^{19}$

Al pretender desligarse del modelo mecánico de aplicación normativa, difundido por diversas lecturas positivistas, Dworkin rechaza la posibilidad de concebir al juez como si fuera un legislador suplente. Para justificar su postura, afirma que el intérprete constitucional tan sólo puede echar mano de argumentos de principio, no de argumentos políticos. ${ }^{20} \mathrm{El}$ que un juez no disponga de una potestad discrecional, o si se prefiere, de un poder de apreciación semejante al del legislador, lo obliga a asumir la obligación de emitir una respuesta correcta ("right answer") ante la controversia planteada. Esto significa, según recordábamos, que la resolución deberá no sólo presentarse en armonía con el orden jurídico existente, sino también como la mejor de las soluciones posibles. ${ }^{21}$

En esta parte de la teoría de Dworkin, esto es, al trazar una conexión entre la tradición histórica del derecho y su proyección al futuro, es donde aparece la figura del juez Hércules. Ese juez ideal, capaz de resolver todos los "casos difíciles" que presentan soluciones múltiples, es para nuestro autor aquél cuyo conocimiento del derecho en su integralidad sólo podría equipararse a la fuerza física del personaje mítico. Frente a esta afirmación, se puede objetar que es entonces este juez ideal, dada su inmensa sapiencia, quien determina unilateralmente el contenido del derecho. Los confines de las normas parecerían determinados, por consiguiente, a partir de un acto eminentemente moral del intérprete. ${ }^{22}$ Por lo anterior, la defensa de su postura consiste en asumir que,

de derecho salvo si consideramos que las verdaderas condiciones de los enunciados jurídicos incluyen consideraciones morales", en Justice in Robes, Cambridge, The Belknap Press of Harvard University Press , 2006, p. 234.

${ }^{19}$ Pariente-Butterlin, Isabelle, "Principes et politiques chez Ronald Dworkin", en Wesche, Steffen y Véronique Zanetti (eds.), Debating Dworkin, Bruxelles, Editions Ousia, 1999, p. 328.

20 "A mi entender, se llega a una apreciación exacta del problema si se considera que, en los asuntos delicados, los jueces tienen razón de fundar sus decisiones sobre consideraciones de principio y no sobre consideraciones de estrategia política”, Dworkin, Ronald, Op. Cit., 1985, p. 11.

${ }^{21}$ Michaut, Françoise, "Law's Empire de Ronald Dworkin”, Archives de Philosophie du Droit, no. 33, 1988, p. 117

22 Para responder a las críticas más frecuentes en este sentido, Dworkin justifica que la mayoría

\section{PRECEDENTE}


para separar de su decisión toda posibilidad de lectura moral de la sentencia, el juez otorga al carácter de integridad del derecho un aspecto funcional en torno al cual la sentencia debe quedar circunscrita.

La intención de este trabajo no es la de probar que la actividad de los tribunales constitucionales europeos los ha colocado, al menos en los pasados cincuenta años, como entidades creadoras de derecho. Nos limitaremos en este sentido a concluir que estos tribunales han efectuado una función doble que, sin duda, podría identificarse con un acto de creación de derecho, que a su vez podría ligarse a la idea de apego a estándares normativos equiparables a los planteados por la teoría de Dworkin. En efecto, el control de constitucionalidad entendido en términos continentales plantea por un lado que la obligación de resolver "casos difíciles" representa una decisión que se toma siempre después de ocurridos los hechos controvertidos, y posteriores a la creación de los parámetros normativos que sirven de base al tribunal para dictar la sentencia. Esta última forma parte de la decisión pública en tanto el juez debe ser un continuador de estas dos líneas que constriñen al respeto de la coherencia del orden normativo. Por otro lado, las decisiones subsecuentes que se acumulan en un corpus de jurisprudencia inspiran cada vez más a los actores políticos formales, es decir, quienes están encargados constitucionalmente de la creación de normas, específicamente las legislaturas y gobiernos, de tal suerte que ciertas elecciones que estos efectúan arrojan un pleno respeto a la coherencia interpretativa que ha sido erigida en las decisiones definitivas pronunciadas por el intérprete máximo de la Constitución.

Si tomamos en consideración que los tribunales constitucionales europeos fueron erigidos, en primer lugar, para deslindar competencias entre las diferentes ramas del poder, podemos entender que la estructura parlamentaria ha concebido la acción de estos jueces para resolver conflictos legislativos existentes. Esto es, que sus resoluciones tendrán como consecuencia aprobar, modificar o censurar una ley una vez que ésta ha sido votada en el hemiciclo. De esta manera, al definir la forma como las reglas constitucionales encuadran

\footnotetext{
de los comentaristas entiendan la práctica del derecho como una operación que se realiza "de dentro hacia fuera", es decir, a partir de la controversia que un cliente plantea al litigante. Este último busca el derecho aplicable al caso. En el extremo opuesto, su propuesta teórica plantea al juez Hércules como ejercitando una operación interpretativa de fuera hacia dentro, es decir, a partir del caso concreto el juez hace una reflexión de la totalidad del orden normativo para tomar una decisión que respete esa integridad que le es intrínseca. Nuestro autor incluso insiste sobre el hecho de que él nunca propuso esta figura para dar puerta abierta a los jueces a inundar sus sentencias de rebuscadas doctrinas. Se trata más bien de efectuar un ejercicio de concordancia entre la sentencia y la situación actual de la moralidad política en vigor. Véase Justice in Robes, 2006, pp. 54-56.enunciados
} 
el trabajo del legislador, el juez constitucional europeo está llamado a producir la Constitución. Un acto de control de constitucionalidad no puede entonces desligarse de representar un "proceso de decisión constitucional". ${ }^{23}$

Basados únicamente en el análisis de la influencia que ha representado la jurisprudencia constitucional europea dentro de la actividad del legislador, basta con advertir que tal intervención parece acentuarse claramente en períodos de crisis. Por su parte, el desarrollo de la Corte Suprema de los Estados Unidos muestra cómo, fuera de situaciones verdaderamente excepcionales, cuyo extremo está ciertamente representado por la crisis de los años del New Deal que llevó al Presidente Roosevelt a la idea inacabada del courtpacking plan, los jueces estadounidenses se apegan a un estricto sentido de la reserva judicial. En este sentido, teóricos europeos han desarrollado una noción formulada originalmente por Charles Eisenmann, que se orienta a afirmar que el juez no toma el lugar del poder legislativo, a menos que él mismo se dedique a elaborar principios no contenidos expresamente en la legislación, y que sea él mismo quien los aplique en seguida en sus sentencias. Es por ello que, frente a la concepción moral de la interpretación dworkiniana, los europeos tienden a mirar al juez constitucional como un factor que podría contribuir a que "el jus-naturalismo encontrara una vez más su paraíso". ${ }^{24}$ Estos temores parecen acaso más fundados en los países donde un conjunto de principios ha sido creado por vía jurisprudencial. Basta pensar en el "bloque de constitucionalidad", que el juez constitucional francés generó a partir de la que es considerada hasta el día de hoy su decisión fundadora. ${ }^{25}$ En estos contextos, las primeras discusiones sobre el peligro de dotar al juez constitucional de poderes excesivos se centran en la posibilidad de que, al detectar fallas en la coherencia constitucional del ordenamiento, los tribunales pudieran iniciar acciones. ${ }^{26}$ Esa posibilidad sigue hasta nuestros días ajena a todas las jurisdicciones de aquél continente. Sin embargo, es preciso preguntarse 54 a estas alturas del desarrollo de tales tribunales, hasta dónde la actividad que desarrollan implica una actividad técnica, o hasta dónde puede ser catalogada como política. En este sentido podremos afirmar que la actividad jurisdiccional que puede ubicarse en la frontera de la decisión política permanece limitada a

\footnotetext{
${ }^{23}$ Stone, Alec, "Judicialization and the Construction of Governance", Comparative Political Studies, no. 32, 1999, pp. 123-125

${ }^{24}$ Hamon, Léo, Les juges de la loi: naissance et rôle d'un contre-pouvoir, le Conseil Constitutionnel, Fayard, Paris, 1987, p. 281.

${ }^{25}$ Nos referimos a la decisión no. 71-44 DC de 16 de julio de 1971, relativa a la libertad de asociación, donde el Consejo Constitucional atribuyó valor constitucional a las disposiciones normativas del preámbulo de una constitución que ya no estaba en vigor, a saber, la de la IV República, vigente entre 1946 y 1958.

${ }^{26}$ Hamon, Léo, Op. Cct., 1978, pp. 174-175.
}

\section{PRECEDENTE}


la operación interpretativa de descifrar el contenido de los principios. Un juez no hace uso de estrategia alguna salvo cuando los miembros de un tribunal son llevados a reaccionar contra situaciones anormales, mismas que casi siempre se presentan cuando se presume que su actuación invade la esfera de los órganos políticos, a saber el gobierno y las legislaturas.

Esta supuesta usurpación de la función legislativa parece ser lo que nutre los descontentos de los partidos que se han visto desfavorecidos por interpretaciones constitucionales adversas a sus intereses. Sin embargo, el debate parlamentario en Europa aparece cada vez mejor estructurado en términos jurídicos, por lo que acusaciones de esta naturaleza son cada vez menos frecuentes, dado que la asimilación de las jurisdicciones constitucionales lleva al elector a confiar cada vez más en la actividad técnica, y no política, de los tribunales. Una acusación infundada de los políticos frente a los tribunales se traduciría, en aquél contexto de normalidad democrática tan enraizada, en una sanción electoral más que en una invitación a votar por determinada opción política en las próximas elecciones. El interés que subyace en el intérprete constitucional europeo se aleja de aspectos estratégicos, morales o de cualquier otra razón que pudieran justificar que el juez interpretara la constitución de cierta manera. Si acaso, puede afirmarse también en el caso europeo, y para retomar la conclusión de Dworkin, que el juez constitucional se erige como la instancia encargada de garantizar que los términos de la ley se encuentran plasmados, de la mejor manera posible, en cada decisión que éstos tribunales están llamados a producir. 